\title{
PENDIDIKAN MULTIKULTURAL DI INDONESIA: ANALISIS SINKRONIS DAN DIAKRONIS
}

\author{
Oleh: \\ Okta Hadi Nurcahyono ${ }^{1}$
}

\begin{abstract}
Abstrak
Proses pendidkan tidak terlepas dari stuktur sosial dan perkembangan masyarakatnya, begitu juga pada pendidikan multikulturalisme. Pendidikan multikultural merukpakan fenommena baru dalam dunia pendidikan, sehingga menjadi daya tarik untuk diperbincangkan dalam forum-forum ilmiah seperti seminar, workshop, simposium dan sebagainya. Artikel ini memaparkan proses dan jalan panjang dan perkembangan pendidikan multikulturalisme di Indonesia. Ada dua pendekatan yang digunakan penulis dalam menganalisis perkembangan pendidikan multikultural di Indonesia yaitu dengan pendekatan sinkronis dan pendekatan diakronis. Dalam pendekatan sinkronis, ditemukan bahwa pendidikan multikultural di Indonesia lahir dari perjalanan panjang yang terbagi menjadi tiga fase yaitu: Fase segregasi pada masa kolonial, fase pendidikan yang bercorak melting pot pada masa orde baru, dan fase pendidikan multicultural dengan semangat demokrasi pada masa reformasi. Sedangkan pada analisis diakronis, pendidikan multikultural yang ada di Indonesia sekarang ini tidak lepas dari sejarah dimasa lampau, yaitu semboyan "Bhinneka Tunggal" sebagai politik kebudayaan di jaman Kerjaan Majapahit dan Peristiwa reformasi yang melahirkan demokrasi dengan menjujung tinggi persamaan hak pada setiap warga negara khususnya dalam mengakses pendidikan.
\end{abstract}

Kata kunci : Pendidikan Multikultural, sinkronis dan diakronis

\footnotetext{
${ }^{1}$ Staff Pengajar Program Studi Pendidikan Sosiologi-Antropologi, FKIP- Universitas Sebelas Maret Surakarta (okta.hadi@staff.uns.ac.id)
} 


\section{PENDAHULUAN}

Indonesia adalah negara multikultural terbesar di dunia. Kenyataan ini suatu taken for granted, dimana negara Indonesia terdiri dari berbagai kelompok etnis, suku, agama, budaya dan lain sebagainya. Pada saat ini Inonesia terdiri dari 13.000 pulau besar maupun kecil, Populasi pendudukanya sekitar 250 juta jiwa dengan berbagai macam keberagamannya, terdiri dari 300 suku, dan 200 bahasa. Selain itu masyarakat Indonesia menganut 6 agama seperti Islam, Kristen, Katolik, Hindu, Budha, dan Konghuchu, serta berbagai macam aliran kepercayaan.

Keberagaman bangsa Inonesia ini dapat menjadi sebuah berkah juga musibah. Menjadi sebuah berkah jika Indonesia sebagai sebuah entitas negara bangsa mampu merawat keberagamannya. Sebaliknya, dapat menjadi sebuah musibah jika bangsa ini tidak mampu merawat keberagaman, seperti disharmoni bangsa yang terjadi dewasa ini. Peristiwa disharmoni sosial yang dipertontonkan di media dan media sosial ini adalah cerminan bahwa negara ini dalam keadaan darurat kesadaran akan keberagaman.

Demokrasi menjadi tantangan tersendiri bagi keberagaman yang ada di Indonesia. Demokrasi merupakan produk dari reformasi pasca 1998. Bangunan Indonesia Baru dari hasil reformasi atau perombakan tatanan kehidupan Orde Baru adalah sebuah "masyarakat multikultural Indonesia" yang bercorak "masyarakat majemuk" (plural society). Corak masyarakat Indonesia yang "bhinneka tunggal ika" bukan lagi keanekaragaman suku bangsa dan kebudayaannya, melainkan keanekaragaman kebudayaan yang ada dalam masyarakat Indonesia (Suparlan, 2002). Strategi politik kebudayaan juga berbeda, jika pada masa Orde Baru keberagaman atau multikulturalisme di Indonesia seperti permadani sedangkan pada masa reformasi ini sudah menyerupai mozaik.

Akhir-akhir ini muncul kesadaran masif dari berbagai lapisan masyarakat tentang pentingnya menjaga NKRI, Bhineka Tunggal Ika, dan kebergaman atau multikulturalisme. Disharmonisasi bangsa akhir-akhir ini karena terjadi friksi antar beberapa golongan baik yang mayoritas dan minoritas atau sebaliknya, sebagai akaibat adanya hajatan politik yakni Maka daripada itu pendidikan menjadi agen sosialisasi yang penting perlu dimanfaatkan semaksimal mungkin agar peristiwa dishamonisasi yang terjadi bisa terhindarkan. Implentasi pendidikan multikultural dianggap salah satu cara yang tepat untuk dapat menanamkan kemampuan masyarakat hidup dalam keberagaman dan rasa saling toleransi antar sesame (Parekh dalam Hanum, 2009).

Pendidikan multicultural merupakan fenomena yang relative baru dalam dunia pendidikan (Tilaar, 2004: 123). Perkembangan pendidikan multikultural ini sejalan dengan perkembangan demokrasi yang ada di satu 
negara. Pada prinsipnya pendidikan multicultural mendambakan persamaan hak, termasuk hak dalam mengakses pendidikan untuk semua orang "Education for all". Begitu juga dengan proses demokratisasi yang dipicu oleh pengakuan hak asasi manusia yang tidak membedakan perbedaanwarna kulit, agama, dan gender (Tilaar, 2014:124).

Pendidikan multikulturalisme di Indonesia manjadi wacana akademik yang cukup menarik sejak awal tahun 2000. Beragam forum akademik seperti seminar, symposium, worshop, dan diskusi publik bertemakan pendidikan multikulturalisme. Beragam pula karya-karya akademik dari hasil penelitian dan kajian akademik yang berwujud buku teks, buku ajar, dan artikel ilmiah juga bertemakan pendidikan multikulturalisme. Milsanya karya Sunarto, Hiang-Khng dan Fedyani (2004), menuliskan perkembangan pendidikan multikulturalisme di kawasan asia selatan.

Banyak sekali artikel yang ada dalam jurnal ilmiah yang ditulis berdasarkan hasil penelitian dan kajian ilmiah. Arikel yang ditulis (Ibrahim, 2008), Hanum \& Rahmadona (2010), (Mania,2010), (Amirin, 2012) dan (Octaviani,2013) mengakaji mengenai pererapan atau implementasi pendidikan multikulturalisme di sekolah. Jarang sekali tulisan baik berupa kajian ilmiah yang menceritakan studi tentang perkembangan pendidikan multikultural yang ada di Indonesia.

Tulisan ini melihat bagaimana pendidikan multikulturalisme sebagai suatu proses panjang dalam perjalanan dunia pendidikan dan siatuasi kenegraan di Indonesia. Hal ini dikaranakan perkembangan dunia pendidikan tidak bisa dilepaskan dari konteks social, ekonomi, politik, dan sejarah suatu bangsa. Sehingga tulisan ini menarik untuk dikaji lebih mendalam mengenai perkembang pendidikan multikulturlasime di Indonesia.

Pendekatan dalam menganalisis perkembangan pendidikan multurlisme di Indonesia pada artikel ini dengan menggunakan pendekatan yang banyak digunakan oleh ahli-ahli sejarah dan antropologi yaitu pendekatan sinkronis dan pendekatan diakronis. Seperti yang pernah ditulis Setyobudi dan Alkaf (2011) yang menggunakan pendaketan sejenis dalam mengakaji kendala multikulturalisme yang ada di Indonesia. Pendekatan diakronis lebih menekankan acuan waktu, penulis gunakan dalam menguji perkembangan pendidikan multikultura dimasa ini dengan sejarah dimasa lalu. Pendekatan sinkronis yang tidak terlalu memperhatikan acuan waktu, menganalisis akar pendidikan multikulturalisme di Indonesia. Berdasarkan dua pendekatan tersebut diharpkan dapat mampu melihat 
bagaimana perkembangan pendidikan multikultural di Indonesia.

\section{Pendidikan Multikultural di Indonesia}

Gagagasan multikulturalisme di Indonesia kembali muncul ke permukaan pada tahun 2002. Hal ini sejalan dengan digulirnya reformasi 1998 dan diberlakukannya otonomi daerah mulai tahun 1999. Pemerintahan orde baru pemerintahan cenderung dijalankan secara sentralistik dengan menggunakan politik kebudayaan yang seragam dan menggunakan tipe pendekatan "permadani" dalam melihat masyarakat yang multikultural. Pasca orde baru desentralisasi berkembang dan kedaerahan turut meningkat, hal ini disadari dapat menimbulakn efek yang kontra produktif jika dilihat dari perspektif kesatuan dan integrasi nasional.

Berkaitan dengan hal tersebut, maka dieperlukannya kembali gagasan diimplementasiakknya multikulturalisme di Indonesia. Pada dasarnya paham multikulturalisme yang tumbuh dan berkembang di Kanada dan Amerika. Paham multikulturalisme sejalan dengan fakta sosial yang sudah ada di Indonesia yakni Bhineka Tunggal ika. Baik antara multikulturalisme dan bhineka tunggal ika memeiliki semangat yang sama yakni : unity in deversity bukan uniformity in deversity. Maka dari dari perlunya penenaman nilai-nilai multikulturalisme yang sejalan dengan Bhineka Tunggal Ika melalui pendidikan.

Penenaman nilai-nilai multikulturalisme juga kebhinekaan melalui jalur pendidikan. Di dunia sudah mengenal yang namanya pendidikan multikultural. Penddikan multikultural ini pendting diberikan kepada anak atau peserta didik dengan harapan agar anak mampu memahami bahwa didalam lingkungan mereka dan juga lingkungan diluarnya terdapat keragaman budaya. Keragaman budaya tersebut berpengaruh kepada tingkah laku, sikap, pola pikir menusia, sehingga manusia tersebut memiliki cara-cara (usage), kebiasaan (flok ways), aturan-aturan (mores), bahkan adat istiadat (cutomes) yang berbeda satu dnegan yang lainya (Hanum dan Rahmadonna, 2010). Pendidikan multukulturalisme juga merupakan transformasi pendidikan untuk menyadarkan masyarakat akan pentingnya pemahaman relatisme kebudayaan (cultural reletivism)(Sunarto, Hiang dan Fedyani, 2004).

Pendidikan multikultural adalah bentuk gerakan reformasi pendidikan di Amerika pada tahun 1960-an. Reformasi pendidikan yang dulunya merupakan pendidikan segregasi atau mengkotak-kotakan kelas sosial, suku agama, dan ras, kemudian berubah dengan memberikan peluang yang sama bagi setiap orang untuk mendapatkan pendidikan. Menurut Banks (2002) ada empat tujuan gerakan multikultural yaitu: Pertama "to help 
individuals gain greater self understanding by viewing themselves from the perspectives of other culture" (membantu individu untuk memahami diri sendiri secara mendalam dengan berkaca dari kacamata budaya lain. Kedua, "to provide student with cultural ethnic alternatives"(membekali peserta didik dengan pengetahuan mengenai etnis dan budaya lain). Ketiga, "to reduce the pain and dicrimination that members of some ethnic groups experience because of their unique racial, physical, and cultual characteristic"(mengurangi derita diskriminasi ras, warna kulit dan karakteristik budaya). Keempat, "to help students to master essential reading, writing, and math skill"(membantu para perserta didik untuk menguasai kemampuan dasar membaca, menulis dan berhitug.

\section{Analisis Sinkonis dan Diakronis}

\subsection{Analisis Sinkronis}

a. Pendidikan Segregrasi

Pendidikan formal di Indonesia sudah berlangsung sejak lama, bahkan dalam catatan sejarah pendidikan sudah ada sejak negara Indonesia belum di lahirkan. Menurut catatan I Tsing pendeta buda yang sempat singgah di Sriwijaya pada tahun 687 masehi, menurutnya Palembang pada masa itu menjadi pusat pendidikan agama Budha. Begitu juga pada masa kedatangan bangsa-bangsa kolonial seperti Portugis dan Spanyol pada abad ke-16.
Misi pendidikan untuk bangsa pribumi kala itu dibarengi dengan motif penyebaran agama Katolik. Pada masa itu terjadi pada pendidikan pada agama Islam yang ada di surau-surau atau pondok pesantren. Jadi pendidikan pada masa pra-Belanda bermotifkan agama dan diperuntukan pada agama tertentu saja.

Pengertian pendidikan yang bersifat segregasi ini pada hakekatnya adalah pendidikan yang memisah atau menggolongkan atar kelompok sosial. Pendidikan segregrasi sangat terlihat pada masa Kolonialisme Belanda. Pada masa ini kaum bumi putra (pribumi/inlender) mendapat pendidikan ala kadarnya. Berbeda dengan kaum bangsawan atau anak keturunan penjajah (Tilaar,2004: 132). Pada proses pendidikan kaum bumi putra sangat terbatas dan tujuannya untuk keperluan penjajah. Tentu saja hal ini sangat bertentangan dengan prinsip pendidikan multikultural, yang dalam prosesnya tidak membeda-bedakan anak bangsa dalam mengakses pendidikan.

\section{b. Pendidikan bertipe melting-pot}

Konsep pendidikan model melting pot menurut Tilaar (2004: 134), merupakan konsep pendidikan dimana masing-masing kelompok etnis dengan budayanya sendiri menyadari adanya perbedaan antar sesamanya. Namun dengan menyadari perbedaan tersebut mereka dapat membina hidup bersama. Pendidikan konsep melting pot di Indonesia, 
terjadi pada paraktik-praktik pendidikan pada masa pemerintahan Orde baru. Pendidikan juga terjadi pada di Amerika, khususnya di Hawai dengan istilah budaya Amerika atau istilah Amerikanisasi.

Praktik pendidikan yang bermodelkan melting pot di Indonesia terjadi pada masa pemerintahan orde baru dengan budaya nasional Indonesia yang berdasarkan nilainilai Pancasila. Hal ini tercermin dalam praktek pendidikan pada semua tingkatan pendidikan. Misalnya dalam penelitian Usman Pelly (2004), terlihat bagaimana politik asimilasi orde baru yang diterapkan pada etnis China di Medan. Dimana para pelajar yang berlatar belakang etnis China digolongkan sebagai pelajar non pribumi. Para pelajar yang berlatar belakang etnis China atau Tionghua mengalami poltik asimilasi dengan cara menyatukan adat istiadat atau tradisi mereka kedalam budaya nasional, contohnya dalam nama dan bahasa.

c. Pendidikan multikultural

Sejalan dengan dibukanya demokrasi di Indonesia, berdampak juga pada proses pendidikan. Pada proses pendidikan menjamin kesamaan hak semua anak bangsa dalam memperoleh pendidikan. Pendidikan multicultural sangat tepat dijalankan di Indonesia mengingat bangsa ini memiliki keberagaman suku, adat istiadat, agama, dan bahasa. Untuk mempersatukan dan memberikan kesadaran akan keberagaman tersebut diperlukannya pendidikan multicultural di Indonesia.

Pada penerapannya pendidikan multikultural di Indonesia diposisikan menjadi tiga yaitu sebagai falsafah pendidikan, sebagai pendekatan pendidikan, dan bidang kajian dan bidang studi (Amirin, 2012), dapat digambarkan sebagai berikut:

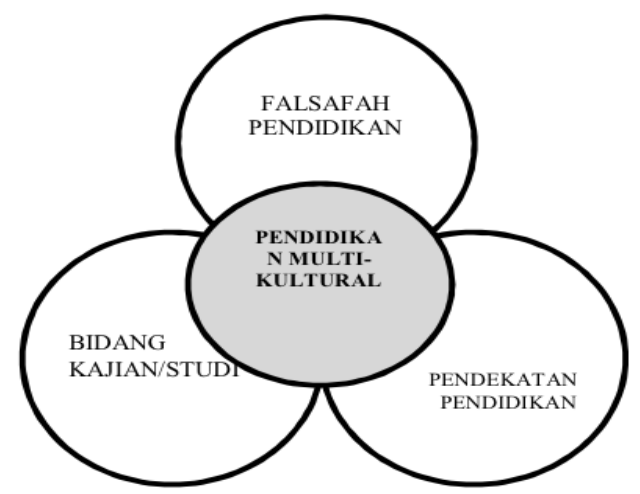

Gambar 1. Implementasi Pendidikan Multikultural di Indonesia

Sebagai falsafah pendidikan, kekayaan dan keberagaman (multikultural) yang dimiliki oleh Indonesia hendaknya dapat dimanfaatkan dalam meningkatkan dan mengembangkan sistem pendidikan. Sebagai pendekatan pendidikan, pendekatan pendidikan yang kontekstual harus memeperhatikan keragaman budaya yang ada. Sebagai bidang ilmu kajian dan studi, yaitu wacana multikulturalisme yang masuk ke dalam mata pelajaran tertentu seperti sosiologi, antropologi dan kewarganegaraan, pada akhir-akhir ini juga ada wacana untuk menjadikan pendidikan multikulturalisem sebagai mata pelajaran tersendiri. Dari ketiga hal tersebut baik sebagai falsafah, sebagai 
pendekatan, dan bidang kajian atau bidang studi belum ada kajian yang spesifik dan detail meneliti ketiga hal tersebut.

\subsection{Analisis Diakronis}

\section{a. Semboyan Bhinneka Tunggal Ika}

Kata Bhinneka Tunggal Ika sering kita perdengarkan dalam setiap jenajang pendidikan. Kata ini sudah menjadi semboyan sejak jaman kerjaan Majapahit. Semboyan ini diambil dari kitab sutasoma karya empu Tantular semboyan Bhinneka Tunggal Ika digunakan Kerajaan Majapahit sebagai politik kebudayaan dalam menjaga keharmonisan kehidupan beragama masyarakatnya. Menurut Kealan (dalam Setyobudi dan Alkaf, 2011) pengertian Bhinneka Tunggal Ika Tan Hana Dharma Mangrua yang berarti, Walaupun berbeda, namun satu juga adanya, sebab tak ada agama yang memiliki Tuhan yang berbeda". Realitas yang pada masa itu Hindu sebagai agama resmi Majapahit, tetapi masih toleran terhadap Buda dan Islam.

Selain itu, dikarenakan wilayah kekuasaan Majapahit yang cukup luas yakni yang dikenal sebagai wilayah nusantara. Dimana membentang dari Semenanjung Melayu hingga Papua melalui Kalimantan Utara membutuhkan alat pemersatu yang memeprsatukan beragam kebudayaan diwilayah kekuasaanya. Pada masa itu Kerajaan Majapahit pada masa kejaannya dipimpin oleh Raja Hayam Wuruk dengan Mahapatih Gajah Mada berhasil menaklukkan kerajaan-kerajaan lain di Nusantara. Oleh karena itu, Empu Tantular menulis kitab Sutasoma sebagai legitimasi kekuasaan membenarkan penaklukan kerajaan lainnya dengan politik pemersatu berupa semboyan Bhinneka Tunggal Ika.

Pada proses pendidikan Semboyan Bhineka Tunggal sangat tertanam kuat di ingatan para peserta didik ketika masa pemerintahan orde baru. Pada masa ordebaru beragam cara menanamkan semboyan tersebut misalnya melalui lambang-lambang Bhineka Tunggal Ika yang ada disetiap sekolah, melalui hafalan-hafalan butir-butir pancasila pada praktek pembelajaran, dan beragam pelatihan seperti pelatihan P4 (Pedoman, Penghayatan dan Pengamalan Pancasila).

Terlepas dari proses internalisasi nilainilai Bhineka Tunggal Ika pada proses pendidikan di masa orde baru, disisi lain identitas-identitas kebudayaan minoritas ditindas dengan berbagai cara dengan mengatasnamakan kesatuan bangsa. Misalanya politik asimilasi yang dikenakan pemerintahan orde baru kepada etnis Tionghua. Dimana politik asmilasi ini sangat bertentangan dengan semangat multikulturalisme. Pada proses Pendidikan 
zaman Orde baru Semboyan Bhinneka

Tunggal Ika diartikan sebagai bentuk uniformitas kebudayaan sejalan dengan meltingpot yang ada di Amerika. Penyeregaman ini sangat terlihat dalam praktek-praktek pendidikan, mulai dari aspek kognitif, afektif maupun psikomotor.

Terebih lagi pendidikan pada masa orde baru dijadikan alat politik untuk melanggengkan kekuasaan. Misalnya para guru khususnya yang berstatus Pegawai Negeri Sipil (PNS) dimobilisasi dalam satu kekuatan politik tertentu. Dengan kata lain pendidikan sebagai alat politik dan pendidikan multicultural belum dianggap penting walaupun realitasnya multi kebudayaan, agama, ras, etnik dan sebagainya. Hal ini sejalan dengan Bhineka Tunggal Ika sebagai poltik pemersatu pada jaman Kerajaan Majapahit dengan motif pelanggengan kekuasaan.

\section{b. Semangat Reformasi}

Reformasi 1998 pasca pemerintahan orde baru membawa angin segar bagi perkembangan pendidikan multikulturalisme di Indonesia. Gagasan multikultural mulai di dengungkan pada era reformasi. Pada dasarnya pendidikan multikultural bukanlah hal yang baru bagi kehidupan masyarakat Indonesia yang beragam baik suku, agama, ras dan golongan.
Pendidikan multicultural pada masa reformasi sejalan dengan dibukanya seluasseluasnya demokrasi. Pada dasarnya demokrasi memberikan ruang dan hak yang sama kepada setiap warga negara untuk dapat bersuara mengeluarkan pendapat, dan hak untuk dipilih dan memilih dengan tidak diskriminatif. Semangat demokrasi juga tercermin pendidikan multikultural, yaitu dengan memeberikan memberikan hak yang sama bagi setiap anak bangsa dalam mengakses pendidikan.

Pasca reformasi padadengan diterbitkannya Menurut UU Nomor 32 Tahun 2004 tentang Pemerintahan Daerah pada Pasal 1 ayat (5) dikemukakan bahwa otonomi daerah adalah hak, wewenang, dan kewajiban daerah otonom untuk mengatur dan mengurus sendiri urusan pemerintahan clan kepentingan masyarakat setempat sesuai dengan peraturan perundang-undangan. Sejalan dengan diterbitkannya peraturan tersebut, pada proses pendidikan juga mengalami otonomisasi dan desentralisasi. Otonomiasasi pendidikan ini tercermin dalam kurikulum yang diterapkan di seluruh tingkat satuan pendidikan. Otonomisasi dijalankan juga dalam proses pendidikan di daerah dijalankan agar pendidikan dapat dijadikan perkembangan kebudayaan Indonesia (Tilaar, 1999: 16). 


\section{DISKUSI}

Perubahan struktur social politik masyarakat, paham nasionalisme baru, tuntutan hak asasi manusia, ditopang dengan arus gobalisasi begitu masif sangat mempengaruhi perkembangan pendidikan. Hal ini dikarenakan pendidikan tidak akan bisa lepas dari srtuktur social dan politik masyarakat. Begitu juga terjadi pada perkembangan pendidikan multikulturalisme, yang sangat tergantung pada perubahan strukstur social masyarakat. Gelombang perubahan yang tergambar sebelumnya akan melahirkan pendidikan multi kulturalsisme dengan barbagai corak (Tilaar, 2004: 125).

Perkembangan multikulturalisme di Amerika misalnya, diawali dari penghapusan prkatik segregarasi dalam dunia pendidikan. Praktik segregasi di Amerika terjadi pada warga negara Amerika yang berasal Afrika (American-Arfican) yang dipelopori oleh Dr. Martin Luther King dengan gerakan Civil Right. Pengapusan system segregrasi dalam dunia pendidikan Amerika berpengaruh terhadap negara tetangganya yakni Kanada. Negara Kanada juga mengalami hal yang sama di negara bagian Quebec, yang dihuni oleh warga negara Kanada yang berasal dari Perancis (Canadian-France). Melelui persitiwa ini mulailah lahir berkembang pendidikan multikultural pada abad ke-20.

Perkembangan

pendidikan multikultural di Indonesia juga tidak lepas dari sejarah dan perubahan stuktur social politik masyarakat. Istilah pendidikan multikultural di Indonesia merupakan istilah baru muncul pada abad ke-20, tetapi praktek-praktek pendidikan multikultural di masyarakat sudah ada sejak jaman Kerjaan Majapahit dengan semboyan Bhineka Tunggal Ika.

Pendidikan multicultural di Indonesia juga mengalami proses sejarah yang panjang dan melelahkan. Mulai dari jaman prakolonial, kolonialisme, jaman kemerdekaan, orde baru, reformasi sampai pendidikan multicultural yang kita jumpai saat ini. Praktek pendidikan multikulturalisme baik di sekolah maupun masyarakat merupakan bagian dari sejarah pendidikan bangsa ini.

Sampai pada titik pendidikan multicultural seperti yang kita jumpai saat ini, pendidikan multikulturalisme di Indonesia sudah mengalami berbagai tahapan atau fase. Mulai dari masa jaman pra-kolonilaisme, fase segrerasi padamasa kolonialisme, fase melting-pot pada masa orde baru sampai pada pendidikan multikutural.

Perkembangan model atau implemantasi pendidikan multikultural juga terus berjalan dewasa ini. Kajian mengenai pendidikan multikulturalisme dan berbagai masalah multikultural yang di hadapi oleh bangsa Indonesia akan terus berkembang. Pengembangan pemikiran multikultural dan pendidikan ini sejalan dengan konteks masalah yang dihadapi oleh bangsa Indonesia. 


\section{KESIMPULAN}

Pendidikan multikulturalisme di Inonesia sudah melalui jalan panjang dan bergamam tahapan. Kehadiran pendidikan multikulturalisme di Indonesia tidak berada diruang hampa. Kehadiran pendidikan multikulturalisme ditengah-tengah masyarakat sejalan dengan gelombang perubahan struksur social dan politik masyarakat.

Dua pendekatan (sinkronis dan diakronis) pada tulisan yang digunakan dalam menganalisis proses hadirnya dan berkembangnya multikulturalisme di Indonesia. Pada analysis diakronis terlihat bagaimana semangat multikulturalisme dalam bidang pendidikan ini tidaklah hadir begitu saja. Pendidikan multikulturalisme pada masa sekarang sangat terkait dengan sejarah dimasa lalu. Peristiwa sejarah itu yaitu semboyan "Bhinneka Tunggal Ika" pada masa majapahit dan Peristiwa reformasi 1998 yang membawa ngin segar demokrasi bagi bangsa ini.
Selain secara diakronis, penulis menganalisis dengan pendekatan sinkronis. Perkembangan pendidikan multikulturalisme di Indonesia dibedakan menjadi tiga fase perkembangan pendidikan antara lain: Pertama, pendidikan segregasi pada masa kolonial dan pra kolonial. Pada masa ini pendidikan hakekatnya bersifat memisah atau menggolongkan atar kelompok social. Kedua, pendidikan bermodalkan melting pot. Dimana masing-masing kelompok etnis dengan budayanya sendiri menyadari adanya perbedaan antar sesamanya. Namun dengan menyadari perbedaan tersebut mereka dapat membina hidup bersama. Ketiga yaitu tahap pendidikan multikultural yang kita jumpai sekarang. Pendidikan multikultural sekarang ini terwujud dalam bentuk falsafah pendidikan, pendekatan pendidikan dan bidang kajian pendidikan.

\section{DAFTAR PUSTAKA}

Amirin, Tatatang M. (2012). Implementasi Pendekatan Pendidikan Multikultural Kontekstual Berbasis Kearifan Lokal di Indonesia. Jurnal Pembangunan Pendidikan: Fondasi dan Aplikasi. Volume 1, Nomor 2012. Halaman 1-16.

Banks, James A. (2002). An Itroduction to Multicultural Education. Boston: Allyn and Bacon

Bhiku Parekh. (1986). The Concept of Multicultural Education. In Sohen Modgil, et.al(ed). Multicultural Education The Intermitable Debate. Londong: The Falmer Press. 
Fedyani Sayfudin, Achmad. (2006). Membumikan Multikulturalisme di Indonesia. Jurnal Antropologi Sosial Budaya ETNOVISI. Vol II. No 1 April 2006. Halaman 3-10

Hanum, Farida dan Rahmadonna, Sisca. (2010). Implementasi Model Pemebelajaran Multikultural di Sekolah Dasar Propinsi Daerah Istimewa Yogyakarta. Jurnal Penelitian Ilmu Pendidikan, Volume 03, Nomor 1 Maret 2010. Halaman 89-102

H.A.R Tilaar, (1999). Pendidikan, Kebudayaan, dan Masyarakat Madani Indonesia, Strategi Reformasi Pendidikan Nasional. Bandung : PT. Remaja Rosdakarya dan Ford Fondation.

H.A.R Tilaar dan Riant Nugroho, (2010). Kebijakan Pendidikan. Yogyakarta: Pustaka Pelajar.

H.A.R Tilaar. (2004). Multikulturalisme: Tantangan-tantangan Global Masa Depan dalam Tranformasi Pendidikan Nasional. Jakarta: Grasindo

Ibrahim, Ruslan. (2008) Pendidikan Multikultural: Era Pluralitas Agama. El-Tarbawi: Jurnal Pendidikan Islam. Vol.1 No.1 (2008). Hal. 115-127

Lexy J. Moleong,(2006), Metodologi Penelitian Kualitatif, Bandung, PT Remaja Rosdakarya

Mahfud, Choirul. (2010.) Pendidikan Multikultural. Yogyakarta: Pustaka Pelajar

Mania, Sitti (2010). Implementasi Pendidikan Multikultural Dalam Pembelajaran. Lentera Pendidikan, Vol. 13 No. 1 Juni 2010: 78-91

Marzali, Amri (2000). Pendidikan Antropologi dan Pembangunan Indonesia. Antropologi Indonesia. No.62 tahun 2000. Halaman 96-107

Octaviani,Laila (2013) Pandatara Dan Jarlatsuh: Model Pendidikan Multikultural Di Sma Taruna Nusantara Magelang. Komunitas 5 (1) (2013) : 112-127

Setyobudi, Imam dan Alkaf, Mukhlas. Kendala Multikulturalisme di Indonesia; Analisis Diakronis dan Sinkronis. Mudra: Jurnal Seni Budaya. Vol.26 No.2 Juli 2011. Halaman 201-2010

Sunarto, Kamanto, Hiang-khng, Russel, dan Sayfudin, Ahmad, Fedyani. (2014). Multicutural Educatian in Indonesia and South Asia Stepping into the Unfamiliar. Depok: Jurnal Antropologi Indonesia

Zuriah, Nurul. (2011). Model Pengembangan Pendidikan Kewarganegaraan Multikultural Berbasis Kearifan Lokalispipalam Fenomena Sosial Pasca Reformasi Di Perguruan Tinggi. Jurnal Penelitian Pendidikan Vol 12 No. 2, Oktober 2011. Halaman 63-72 

